\title{
SEMILLERO DE INVESTIGACIÓN EN DROGAS PULSIONES, ESTÍLOS PARENTALES, DECISIONES Y DROGAS
}

\author{
Docente \\ Julián Andrés Hernández Gómez \\ jahernandezgom@poligran.edu.co \\ Estudiantes \\ Harman Narváez, Nicolás Riveros, Nicolle Ramírez, Rubén Patiño, Laura Marulanda, Wendy Sierra, \\ Juanita Castro. \\ Institución universitaria Politecnico Grancolombiano. \\ Programa de psicología
}

\begin{abstract}
Nuevo año, nuevas preguntas, nuevas personas, nuevas investigaciones. Respecto a la investigación "Pulsiones y Drogas" que venimos desarrollando desde el 2019-2. Se debe recordar que para la presente investigación se indago y utilizo la teoría clásica de Freud, la cual establece a manera muy general que el ser humano desde un principio buscaría satisfacer o descargar la sensación de placer. Sin embargo, con el tiempo madura y va aprendiendo que esa descarga debe postergarse, hallando nuevos modos que sean aceptables y ajustables a esa realidad. Lo anterior, estaría pues ligado al concepto de "Trieb" o pulsión, y sus cuatro elementos que estarían presentes durante todo el proceso (Freud, 1930). A partir de ello, se han generado adelantos importantes, entre estos la primera salida a recogida de datos.
\end{abstract}

En esta salida pudimos evidenciar y analizar la explicación Freudiana de los cuatro componentes de las pulsiones (Freud, 1979), donde a través de la autoetnografía (Blanco, 2012) evidenciamos la fuerte influencia social como fuente psicológica para el consumo, llevando esta a la realización del esfuerzo que contempla desde el ejercicio de salir de casa para reunirse con sus compañeras y compañeros; y participar en la reunión social en la cual se incluye el consumo de sustancias. El objeto, por otro lado, es regulado de una u otra manera por el grupo social, quien ejerce presión directa al invitar a la persona a consumir; $O$ indirecta al exaltar el consumo propio siempre en relación con un entorno. El objeto termina siendo entendido como un amplificador de la percepción tanto social, como física y sensorial de toda la reunión. Finalmente podemos encontrar que la vivencia de la meta (satisfacción en todo caso) no es únicamente el resultado del uso del objeto (la sustancia), sino que se relaciona con tantas variables como las vividas en el entorno. Como conclusión parcial es importante resaltar que siempre y cuando no se sobrepase la barrera de la tolerancia de la dosis, siempre habrá posibilidad de lograr la meta; sin embargo, si se sobrepasa se convertirá en una vivencia totalmente opuesta donde lo que se experimentará en mayor medida será la sensación de displacer.

Por otro lado, damos la bienvenida a nuestras nuevas integrantes que llegan con energías renovadas para proponer nuevas aproximaciones

investigativas respecto a las drogas. Con ellas surgen nuevas dudas, en este caso nos empezamos a relacionar con el entorno familiar y su relación con el consumo de sustancias en jóvenes y nos empieza a llamar mucho la

\section{POLIANTEA}


atención su influencia en la decisión de consumo. Planteamos con estas nuevas ideas cómo desde el inicio de la ruta educativa se debería tanto educar como prevenir acerca del consumo y sus posibles consecuencias en busca del consumo consciente y responsable. De la misma manera nos interesa el por qué los padres de familia encuentran dificultad en abordar este tema en la familia, y en muchas ocasiones se termina dejando la responsabilidad de abordar el tema de las sustancias únicamente en los entornos educativos formales, teniendo en cuenta que pueden no brindar la orientación que padres y madres querrían dar. Además, dentro de la búsqueda en diferentes fuentes bibliográficas se evidencio que, no hay mucha información acerca del consumo responsable, por el contrario, se evidencia más investigaciones sobre la prevención y consumo problemático. En consecuencia, con esto se intenta que el modelo parental más allá de tener una perspectiva preventiva y de tratamiento, se pueda guiar hacia el acompañamiento del consumo.

Encontramos una alta importancia en profundizar el por qué se tiene en lo general una percepción negativa por parte de los padres de familia, pero por el contrario una percepción positiva o imparcial en algunos jóvenes, lo que genera conflictos intrafamiliares por los choques de ideologías
(Saravia, Gutierrez y Frech; 2014).

Bibliografía

Blanco, M. (2012). Autoetnografía: una forma narrativa de generación de conocimientos. Andamios. Revista de Investigación Social 9 (19). 49-79.

Freud, S. (1930). EL malestar en la cultura. Biblioteca libre Omegalfa. Recuperado de: https://www.omegalf a.es/autores.php?letra ff\#

Freud, S. (1979). Sigmund Freud obras completas volumen 14. Buenos Aires, Argentina: Amorrotu editores $\mathrm{S}$. A.

Saravia, J, Gutiérrez, C y Frech, H. (2014). Factores asociados al inicio de consumo de drogas ilícitas en adolescentes de educación secundaria. Revista Peruana de Epidemiología 18 (1). 17. Tomado de: https://www.redalyc.o rg/pdf/2031/203131355 003.pdf

\section{POLIANTEA}

